\title{
What does it mean to live after heart transplantation? The lived experience of heart transplant recipients. A qualitative study
}

\section{BACKGROUND}

Despite significant improvements in physical state after heart transplantation, the majority of adult patients struggle with continuous psychological distress. The aim of the study was to explore the lived experiences of adult heart transplant recipients in order to understand the inner background of these difficulties.

\section{PARTICIPANTS AND PROCEDURE}

Unstructured, in-depth interviews, based on the Life Story Interview of D. P. McAdams, were performed with 8 adults, aged between 50 and 60 years, who had undergone heart transplantation a year before the research was conducted. Interviews were tape recorded and transcribed verbatim. Data were analysed using narrative methods.

\section{RESULTS}

The central themes of the patients' lived experience were the illness itself and the feeling of being very different

\begin{abstract}
from others and from oneself remembered in the past the times before the transplantation. The experienced discordance between their inner world and the expectations to get better presented by other people (the family, health care workers, etc.) implies that these patients struggle with others' lack of understanding and therefore suffer from a lack of effective psychological support.

\section{CONCLUSIONS}

This study shows that the life stories of patients after heart transplantation are in fact stories of their illness and the consequences it brought. It seems important to take this into consideration when constructing rehabilitation programmes for these patients in order to offer them the most effective support possible.
\end{abstract}

KEY WORDS

lived experience; heart transplantation; narratives

ORGANizATION - 1: Faculty of Psychology, Warsaw University, Warsaw, Poland · 2: Laboratory of Medical Simulation,

Human Anatomy Department, Medical University of Lublin, Lublin, Poland

AUthors' CONTRIBUtions - A: Study design - B: Data collection - C: Statistical analysis - D: Data interpretation .

E: Manuscript preparation · F: Literature search · G: Funds collection

CORRESPONDING AUthor - Prof. Anna Cierpka, Faculty of Psychology, Warsaw University, 5/7 Stawki Str.,

00-183 Warsaw, Poland, e-mail: Anna.Cierpka@psych.uw.edu.pl

to Cite this ARTICLE - Cierpka, A., Małek, K., \& Horodeńska, M. (2015). What does it mean to live after heart

transplantation? The lived experience of heart transplant recipients. A qualitative study. Health Psychology Report,

3(2), 123-130. DOI: 10.5114/hpr.2015.49678

RECEIVED 16.09.2014 · REVIEWED 14.10.2014 · ACCEPTED 02.11.2014 • PUBLISHED 16.02.2015 


\section{BACKGROUND}

There is no doubt that having a serious illness that puts one's life directly at risk is a traumatic event for an individual. The development of an ill person is governed by the same principles as that of a healthy person. However, the sick meet additional obstacles and problems that arise from the particularities of a given condition and how one adapts to that condition. A sickness that is a threat to one's life signifi-
Anna Cierpka, Karolina Małek, Magdalena Horodeńska cantly changes one's personal, family and work-related situations. Frequently it is associated with changes in one's levels of ability, sometimes with disability and dependence on others. Sometimes patients experience changes in the way they look. The attitude towards the body changes. For some it becomes a burden or barrier or causes pain. The body fails and is unable to perform the tasks one expects of it. Both the wider and narrower social contexts, in which an individual needs to function, change due to illness. Apart from the need to reformulate past life roles, there is a need to adapt to the role of a patient. An illness can overthrow the social functioning of an individual. Limited functioning, burdensome symptoms and the need to alleviate them, repeated hospitalizations and time-consuming therapies influence the social relations of a sick individual. Limiting the scope of one's social interactions, they cause progressive social isolation. Both the symptoms and the treatment process often necessitate a career change, or even complete resignation from professional activity. As a consequence, the economic situation of the sick individual and their family worsens.

Illness, together with the above-mentioned changes, generates experiences that are difficult to deal with. Even if the symptoms are successfully controlled, the individual is forced to cope with the awareness of having a condition that is a threat to one's life. This causes fear and anxiety and forces one to look back on one's life and reflect on oneself. An illness may also make impossible or hinder the fulfilment of one's plans and life goals. It might pose a threat to the individual's system of values. It is usually necessary to make re-evaluations, and change the hierarchy of at least some of the values. Different values - ones possible to achieve in the new situation - may come to the fore. The sphere of one's values is challenged by a new, difficult life experience, and it is important what one does with that experience. Being informed about having an illness, or the necessity to undergo serious surgery, can threaten one's sense of identity. According to some reports, in the face of an illness an individual might feel a lack of continuity and cohesion. This is related to changes in the way one experiences oneself (Little \& Kim, 2000).

In this context, it seems both important and interesting to ask a question about experiencing life after a critical life-saving medical intervention that puts an individual at the border between life and death - a heart transplant. Individuals who have undergone a heart transplantation experience all of the above-mentioned difficulties. At the same time, their psychological situation seems even more complicated.

\section{PARTICULARITIES OF THE PSYCHOLOGICAL SITUATION OF INDIVIDUALS WHO HAVE UNDERGONE HEART TRANSPLANTATION}

Research suggests that apart from having to cope with the consequences of the life-threatening situation, patients with heart transplants experience additional difficulties associated with losing their own heart, and accepting the heart of the donor - 'accepting it as one's own' (Rogers, 1989). According to some researchers, exchanging one's own heart for somebody else's (received from an anonymous donor) is a serious threat to a patient's sense of self (Bunzel, Wollenek, \& Grundböck, 1992). Some patients even fear that the new heart will change their personality - the way they sense and react. It is associated with the culturally accepted perception of the heart being the locus of emotions, vitality and the soul (Lakoff \& Johnson, 2003). It occurs despite the fact that in pre-transplantation preparation patients are taught to perceive the heart as a pump, just one of many organs (Shapiro, 1990). Some studies even suggest that the difficulties related to the psychological acceptance of the transplanted heart as one's own can be associated with a worse physiological response and higher risk of transplant rejection (Rauch \& Kneen, 1989).

For the same reason, patients' frequent fears about the fate of their own heart are important. Many patients experience grief after the loss, attributing a great symbolic meaning to their heart ("the heart, that I got from my parents", "the heart, that loved its son") (Kaba, Thompson, Burnard, Edwards, \& Theodosopoulou, 2005; Svenaeus, 2012).

Some reports note another difficulty - a great sense of guilt in relation to the donor. Patients know that their life is only possible through the donor's death (Rauch \& Kneen, 1989; Kaba et al., 2005). As a consequence, they often face ethical dilemmas, the aforementioned sense of guilt, and doubts about their prior system of values. All of these subjective sensations are much more common among people with heart transplants than transplants of other organs (kidney, liver, etc.). This is due to the strong perception of one's own/not one's own heart - the patient constantly feels and hears the heartbeat - how it speeds up during physical effort and slows down at rest. The sensation of the transplanted organ is relentless (Svenaeus, 2012).

The presented picture suggests that experiencing heart transplantation is a particular threat to 
the sense of identity of an individual, which may be associated with a decline in psychological functioning - also seen among patients who undergo a successful transplantation. One should not forget that a successful transplantation does not equal the end of illness. A question of significance to one's identity remains - is a person with a heart transplant healthy, or still a sick individual?

A lot of scientific reports point towards the fact that the significant improvement of one's physical state is not accompanied by an improvement of psychological functioning. The opposite seems to be true - research suggests that, despite continuous improvement in physical functioning, many patients report problems of a psychological nature (Reyes \& Evangelista, 2003; Bunzel et al., 1992). According to a meta-analysis by Dew and DiMartini (2005), about $63 \%$ of patients deal with mood disorders (major depressive disorder [MDD] or dysthymia, according to DSM IV criteria), and about $21-26 \%$ experience anxiety disorders (general anxiety disorder [GAD], post-traumatic stress disorder [PTSD], panic attacks).

Different studies indicate that the symptoms of psychological distress measured in the period of 2 years after the transplantation are directly correlated with the low levels of perceived general quality of life (measured using the SF-36 questionnaire) and worse psychosocial functioning of patients (Baranyi, Krauseneck, \& Rothenhausler, 2013).

It may be that the decline in psychological well-being of transplant patients is related to difficulties with the reconstruction of the narrative of their identity. Research shows that the ability to form a coherent story after a traumatic event is associated with more adaptive styles of coping, and faster recovery (Pennebaker, 1999). The process of creating structured narratives shown by individuals who have experienced a trauma is also correlated with a decreased number and intensity of PTSD symptoms (van Minnen et al., 2002). If we assume that the process of constructing one's identity is the creation of a coherent, understandable narrative about oneself that gives sense and meaning ${ }^{1}$ (McAdams, 1994), we can consider the distorted structure of such a narrative and problems with story telling to be a psychopathology. Instead, the process of recovery consists of telling one's new life story, one that includes the difficult experiences (Tuval-Mashiach \& Calhoun, 2004).

\section{THE NARRATIVE IDENTITY OF AN INDIVIDUAL IN THE SITUATION OF A TRAUMA}

The concept of McAdams, according to which the identity of an individual is continuously constructed, evolving narrative, story of life or a personal myth, is the theoretical basis for the current research (McAdams, 1994, 2006). It is based in the belief that language plays an important role in the creation, interpretation and understanding of reality.

According to McAdams, the problem of identity is most of all a problem of unity and cohesion within an individual, finding the sense of purpose and meaning in life and ascribing meanings to experiences within the narrative. Constructing a narrative about one's own life is a way of organizing episodes, descriptions of objects, actions and possible interpretations in time and space. As the time passes, and one gathers new experience, the auto-narrative is altered, refined and developed. It is therefore a dynamic, constantly changing story of life - both already shaped and still being created.

Therefore, if the development of identity is a development of their personal narrative, it can be said that it does not have a straightforward linear structure. Its structure is hierarchic - the entirety defines the importance of the parts it consists of. The process of development does not take place when certain events take place, but when they are integrated into the personal narrative, in such a way that they are in line with what was before, and what will happen next (Carr, 1986). The individual subjectively determines the causal relations between facts, gives them meaning by relating them to the entirety of the biography and vice versa.

Many researchers have tried to answer the question of what the characteristics of a 'good' self-narrative are. Essentially, this question concerns the identity of an individual. Therefore, can one pinpoint features of a narrative that could indicate the level to which an individual managed to better define their identity?

According to McAdams, the first such feature is narrative coherence (McAdams, 2006), allowing for the understanding of the narrative in a given social context. Constructing a story that is comprehensible not only to the teller, but also to other people, is extremely important - it allows for effective negotiation of meanings in the given social context, and thus full participation in social life and culture (Gergen, 2001). This is because the narrative identity of an individual, as well as other stories through which they try to understand the surrounding world, are 'socially co-created' (Gergen, 2001).

Complexity is another characteristic of a fully formed narrative identity. The more threads exist within the clear structure of the story, the clearer the description of various roles undertaken by the character-author (the so-called imago), and the better defined the identity of the individual (McAdams, 1995, 2006).

As already mentioned, narrative identity is a constantly evolving story about oneself where new experiences of an individual are continuously added, and through which it is possible to discover the meaning of these experiences. However some situations are very difficult, and they can break the narrative thread. This happens when suffering distorts the abil-
The lived experience of heart transplant recipients. A qualitative study 
Anna Cierpka,

Karolina Małek, Magdalena Horodeńska ity of an individual to tell the story, and it becomes 'impossible to narrate' (Riceour, 1992).

In the face of extremely difficult events, such as a serious illness, the individual loses the ability to construct meaningful narratives, and experiences lack of self-coherence (Little \& Kim, 2002). A traumatic event seems to be incoherent with the plot of the narrative. At the same time it is so significant that in order to enable its inclusion in the narrative, the whole structure of the narrative would have to be changed, 'the story would have to be told anew' (Neimeyer, 2006), as the event makes the previous version of the story of life lose its meaning (Little \& Kim, 2002). Apart from that, the individual experiencing a trauma feels a lack of coherence and continuity in time. The past self is unable to explain the present self. This lack of continuity between the past and the difficult present makes it impossible to construct any kind of vision of the future. The person experiencing a trauma is unable to tell a credible story about what they will become (Sewell et al., 2002). Therefore an individual becomes immersed in the present. The lack of ability to refer to the past (which seems devoid of meaning) and the future makes it impossible to look at the current experience from a different perspective - which is key to being able to describe it. Using the narrative terminology, one could say that the person experiencing the trauma is the main character of the story, but they cannot become an omniscient narrator. Research shows that narratives of people affected by trauma are characterized by distorted structure (Salvatore et al., 2006). They can be chaotic, multithreaded, where the number of digressions makes them incomprehensible. On the other hand, they may be characterized by a very rigid structure and content. This rigidity may manifest itself as a compulsive attachment to the narrative from before the trauma, thereby negating the trauma or reducing the whole story to this critical event, which fosters the state of the aforementioned 'immersion' in the difficult present (Neimeyer, 2006).

Qualitative research based in phenomenology, and so reaching into the direct first-person experiences of the subjects, are of significant use for describing the experience of having an illness, being especially helpful for understanding the process of undergoing a transplantation (Kaba et al., 2005). From the phenomenological perspective the lived experience, as described by the subject (in first-person), and not the dry, "scientific" statistical approach becomes the essence of investigations (Svenaeus, 2012). Individuals with heart transplants have a particular individual experience, related to their specific condition, which significantly influences the perception of self and the situation one is in.

Therefore the question these studies asked was how people with heart transplants experience their existence - in other words, what stories of their lives do they construct, and in these stories, what meanings do they give to their personal experiences?

\section{PARTICIPANTS AND PROCEDURE}

Heart transplant patients $(n=8)$ of both genders (one woman, seven men) aged 50-60 (mean age $=56$ ) were invited to take part in the study. Before the surgery, they all suffered from chronic heart failure associated with dilated cardiomyopathy, end-stage hypertrophic cardiomyopathy, ischaemic cardiomyopathy and endstage valvular heart disease. The subjects had undergone heart transplantation surgery a year before the commencement of the current study, and in that period they were not under psychotherapeutic care.

The current study was conducted in the Institute of Cardiology in Warsaw, during the hospitalization of the patients for a routine check biopsy of the heart muscle, taking place exactly one year after the transplantation surgery. Collection of the narrative interviews took place during individual conversations with each of the patients. Every such meeting would last for about an hour. The patients were informed about the goal and the form of the study and could provide or refuse consent to take part in the project. They were asked to tell the stories of their lives, according to the instructions provided by the researcher. The instructions were based on a fragment of the original narrative interview by McAdams (1995), and they included a request for the subject to tell their life story in a way that resembles a book, recounting the events and experiences in successive chapters ${ }^{2}$. The interviews were recorded, and then carefully typed. The content of the resulting material was carefully analysed.

\section{RESULTS - THE ANALYSIS OF NARRATIVE MATERIAL}

The categories for the analyses of the content of the obtained narrative include the analysis of thematic threads and their categorization and also an attempt to find the central rule governing the order of the contents of a narrative.

\section{THEMATIC THREADS AND THEIR CATEGORIZATION}

Thematic threads are short (a few, or even one sentence long) parts of the narratives. Change of time, place, action, subject or object of the story were the criteria for distinguishing between separate threads (see Cierpka, 2000). The selected thematic threads were classified into categories. Thirteen such categories were distinguished during the analysis of the ob- 
tained narratives. Table 1 includes the names of categories and examples of text excerpts classified into those categories. It also provides the part of the identity narrative a given category of threads belong to.
It is worth noting that the threads directly related to experiencing the transplantation process together constituted as much as $75 \%$ of all the threads distinguished within the narratives.

Table 1

Categories of thematic threads

\begin{tabular}{|c|c|c|}
\hline Categories of thematic threads & Examples & $\begin{array}{l}\text { Percentage of occurrence } \\
\text { of threads from a given } \\
\text { category in the narrative }\end{array}$ \\
\hline
\end{tabular}

The education period

Meeting the spouse

Married life

Children

Relationship with children

Myself - ill

Others and my illness

Individual in the face of death

Changes after the transplantation - physical well-being

Changes in the emotional self

The donor

New values

Future
"I went to school, then another school and university, and obviously in high school I was in boy scouts."

"I met my husband at work, we used to sit opposite each other."

"She is still a great girl ...those

30 years ago... but it is still pleasant now."

"I have one son, but he does not want to get married."

"Only now the time has come that I want to tell him (my son) some certain things."

"When you're ill like me, the continuum of life ends. I am becoming an object of care, there are fewer and fewer things that I can do on my own."

"When I needed blood, my friends would come and donate."

"Directly before the surgery I was saying goodbye, leaving the stage. I did not plan anything, I would not even buy a new pair of shoes."

"It is completely different now. I had to be very careful before. I have more strength, I can walk short distances on my own, get out of the house."

"I became so emotional after the transplantation. I tear up easily, I somehow became more sensitive. I don't know where it came from must be that new heart."

"I don't even know if it was a man or a woman."

"Not hurting others became the most important. It is new, it is the most important and it is good. And I want it that way."

"What can I even expect of life? I try not to be too demanding, I don't think about the impossible."
The lived experience of heart transplant recipients. A qualitative study 
THE CENTRAL RULE GOVERNING THE ORDER OF THE CONTENTS OF A NARRATIVE

It is assumed that the structure of a narrative may be based either on a chronological rule, according to which the events are ordered by the real time of their occurrence, a rule that orders the story according to a certain thesis, or a "stream of consciousness" (Dryll \& Cierpka, 1996). One of the narratives was classified in the latter category. It was unstructured, chaotic, the threads were loosely interweaving, and there was no thematic, causal or temporal agreement between them. In the remaining seven analysed accounts, the story's structuring rule was the subsequent stages of the illness. Such construction of a narrative is atypical. The provided instruction to tell about one's life as if it were a book usually leads to chronological stories - and so it begins with birth, growing up, and subsequent stages of education (see Cierpka, 2013). This chronological method of ordering the content was absent in the analysed narratives. Virtually all of the stories were anchored around the experience of illness and undergoing the heart transplantation procedure. The observed regularities will be discussed in the following section.

\section{DISCUSSION OF THE RESULTS}

The conducted analyses reveal some specific features of identity narratives in subjects with heart transplants. A relatively small number of thematic threads, the predominance of threads regarding experiences connected to illness and the undergone procedure, as well as organising the narrative content 'around the illness' seem to justify the thesis about the difficulty amongst the studied individuals in reconstructing their life stories in a way that gives the story an integrative power (integrating the past experiences - including from before the illness, the present and the future). It seems that going through the illness and the transplantation is such a difficult experience it makes it impossible for the existing structure of meaning to assimilate it. It destroys, or puts in doubt, the previously adequate method of organising the identity narrative. In the face of the traumatic event the previous version of the story loses its explanatory meaning (regarding the individual's identity), and the past events lose their significance (this is exhibited in the small number of threads regarding the life and functioning of the patient before the exacerbation of the disease). Therefore there is no possibility to give meaning to what is happening at the present moment. It also becomes extremely difficult to refer to the past, construct scripts for actions and make plans, which is especially important for undertaking different kinds of goal-oriented activities.

The results also irrefutably confirm the thesis that an ongoing problem causes selectiveness in the events included in an autobiography - individuals include in their autobiographies only what is currently the most important for them (Cierpka, 2013). The choice of memories selected from the resource of the acquired experiences is not accidental. We choose the elements that are important for the Self at a given moment - consciously and unconsciously searching the memory for certain events. However, in the currently studied group we have an unusual situation - a kind of a 'narrative loop' forms around the experience of illness. This loop narrowly defines an individual in the 'Myself, ill, after a heart transplantation' category.

A depleted, single-threaded narrative emerges that is limited in terms of content, which may make it impossible to move beyond a defined understanding of self and look for new meanings.

It is worth remembering that none of the analysed stories were ordered according to a real chronology. One could also seek the explanation in a collision with the experience of waiting for the transplantation, which is associated with a paradox of asynchrony of time. The time of waiting for the new heart seems longer than it is, but the same time when measured in terms of the progression of the illness and threat to life speeds up in parallel. A subjective prolongation of the limited time or ignoring the measurable passing of time might take place. The usually unconscious strategies of changing the temporal 'orientations' might aid this - an intensification of the present, future orientation or directing the conscience onto the past. Therefore the ordering of the life story according to the 'time of the illness', its stages and not the real time is, on one hand, a distortion of a good story, but on the other it may have some important function.

Another important issue associated with the context of the current study should not be left out. The narratives were collected in the Institute of Cardiology during the hospitalization of the subjects. Such a context undoubtedly could prompt the individuals to speak about the illness, its symptoms and health problems in general. The patients were surrounded by medical personnel, other sick people, and were aware of the gravity of the check-up visit.

The placement of the experience of constructing a narrative about themselves in such circumstances could cause the subject to create selective stories, located in the closest reality surrounding them. This limitation of the current study necessitates verification of the observations in a semantic context that is neutral for individuals with heart transplants.

\section{CONCLUSIONS}

The presented research material was a first attempt to explain the specifics of how individuals with heart 
transplants function using narrative methods and qualitative analysis. The narrative approach allowed the authors to learn about each personal experience and get through to individual meanings while maximizing respect for the subjects and recognising their borders.

The presented theoretical approach, treating the experience of heart transplantation in the categories of a traumatic event, and so impossible to assimilate, may shed a new light on the problem of functioning in post-transplantation patients, complementing the reports present in the literature that are based on rigid, quantitative analyses. However, it is possible to look more broadly at both the investigated topic and the method of the presented study. Living with an illness is a continuous confrontation with a biographical experience. The experience of an illness is associated with a necessity to relate to the new situation, and the self in that situation. Sometimes the painful sensation of being different may be a factor allowing for a conscious effort to work on oneself. The narrative may then take a different voice, telling the story from a different perspective. Unleashing new voices seems to have a therapeutic function. The problem seems to exist when important aspects of human experience are not reflected in the story told, when the story contains other interferences such as a lack of substance, periodic incoherence or strong identification with the role of a patient, all of which may lead to a distortion in the sense of continuity of Self. There are methods of psychotherapy that aim at improving the individual's functioning by actively working on the self-narrative - remembering the threads about having a sense of strength, competences, development - fragments aiding a constructive reorganization of the story about oneself (White \& Epston, 1990; Payne, 2006; Tokarska, 2002). In medicine, in the process of treatment this would mean everyday use of the knowledge in this area by the medical personnel. In contact with the patient it would be worthwhile to pay attention to their self-narrative, support its development and not silence it with a dominating clinical narrative. The need to offset the negative emotional effects of technicisation and dehumanization in medicine is increasingly stressed among medical personnel. It may be that an effort to read the meanings ascribed to the illness by the patients could be a practical method to counter the negative psychological effects patients can experience. In practice, there is a great temptation to organize the chaotic and incomplete narratives of patients and compliment them with the practitioner's interpretation of the patient's problems. However, the key here is for the patient to remain the author of the narrative, while also being its main character. Encouraging patients to speak about their most important values, as well as roles different to that of being an ill person, might help them maintain the continuity of their story. It might foster the creation of a richer, multi-threaded self-narrative, allowing them to re-create themselves.

\section{ENDNOTES}

1 Narrative identity is defined as an "internalized and developed life story or a personal myth that unites a reconstructed past, perceived present, and anticipated or expected future into a narrative configuration to provide feelings of unity, continuity, and aim" (McAdams, 1994, pp. 746-747).

2 Think about your whole life: about what was, what is and what will be, as if it were a book, the chapters of which tell about the main stages of your life's course. Give each one of these chapters a title and describe its main contents.

Pay special attention to turning points, which were an end to one stage and the beginning of another. At the end write a chapter about your future - things that will be. Look again at the chapters of the book about your life and try to give it a title that reveals its main topic - present in all its parts and connecting them, giving them meaning.

\section{References}

Baranyi, A., Krauseneck, T., \& Rothenhäusler, H. B. (2013). Overall mental distress and health - related quality of life after solid - organ transplantation: results from a retrospective follow - up study. Health and Quality of Life Outcomes, 11, 1-10.

Bunzel, B., Wollenek, G., \& Grundböck, A. (1992). Living with a donor heart: Feelings and attitudes of patient towards donor and donor organ. Journal of Heart and Lung Transplantation, 11, 1151-1155.

Carr, D. (1986). Narrative and the real world. An argument for continuity. History and Theory, 25, 117-132.

Cierpka, A. (2000). Metody analizy narracji w badaniach psychologicznych [Methods of analysis of narratives in psychology research]. In: M. Straś-Romanowska (ed.), Metody jakościowe w psychologii wspótczesnej [Qualitative methods in current psychology] (pp. 129-139). Wroclaw: Wydawnictwo Uniwersytetu Wrocławskiego.

Cierpka, A. (2013). Tożsamość i narracje w relacjach rodzinnych [Identity and narratives in family relations]. Warsaw: Eneteia, Wydawnictwo Psychologii i Kultury.

Dew, M. A, \& DiMartini, A. F. (2005). Psychological disorders and distress after adult cardiothoracic transplantation. Journal of Cardiovascular Nursing, 20, 51-66.

Dryll, E., \& Cierpka, A. (1996). Badanie treści etosu rodzinnego poprzez analizę narracji [Studying the
The lived experience of heart transplant recipients. A qualitative study 
Anna Cierpka, Karolina Małek, Magdalena Horodeńska substance of family ethos through analysing narratives]. Kwartalnik Polskiej Psychologii Rozwojowej, 1, 33-52.

Gergen, K. J. (2001). Psychological science in postmodern context. The American Psychologist, 56, 803-813.

Kaba, E., Thompson, D. R., Burnard, P., Edwards, D., \& Theodosopoulou, E. (2005). Somebody's heart inside me. A descriptive study of psychological problems after heart transplantation. Issues in Mental Health Nursing, 26, 611-625.

Lakoff, G., \& Johnson M. (2003). Metaphors we live by. Chicago: University of Chicago Press.

Little, M., \& Kim, P. (2002). Survivorship and discourses of identity. Psycho-Oncology, 11, 170-178.

McAdams, D. P. (1994). The person: An introduction to personality psychology. Fort Worth, TX: Harcourt Brace.

McAdams, D. P. (1995). What do we know when we know a person? Journal of Personality, 63, 265-396.

McAdams, D. P. (2006). The problem of narrative coherence. Journal of Constructivist Psychology, 19, 109-125.

Neimeyer, R. (2006). From chaos to coherence: Psychoterapeutic integration of traumatic loss. Journal of Constructivist Psychology, 19, 127-145.

Pennebaker, J. W. (1999). Forming a story. The health benefits of narrative. Journal of Clinical Psychology, 55, 1243-1254.

Payne, M. (2006). Narrative Therapy. An Introduction for Counsellors. London: Sage Publications.

Rauch, J. B., \& Kneen, K. K. (1989). Accepting the gift of life: Heart transplant recipients postoperative adaptive tasks. Social Work and Health Care, 14, 47-59.

Reyes, C. J., Evangelista, L. S., Doering, L., Dracup, K., Cesario, D. A., \& Kobashigawa, J. (2004). Physical and psychological attributes of fatigue in female heart transplant recipients. The Journal of Heart and Lung Transplantation, 23, 614-619.

Riceour, P. (1992). Filozofia osoby [The philosophy of a person]. Krakow: Wydawnictwo Naukowe PAT.

Rogers, K. M. (1989). Nature of spousal supportive behaviour that influence heart transplant patient compliance. Journal of Heart Transplantation, 6, 90-95.

Salvatore, G., \& Conti, L. (2006). Disorganized narratives: problems in treatment and therapist intervention hierarchy. Journal of Constructivist Psychology, 19, 103-108.

Sewell, K. W., \& Williams A. M. (2002). Broken trauma narratives, metaconstructive gaps and the audience of psychotherapy. Journal of Constructivist Psychology, 15, 205-218.

Shapiro, P. A. (1990). Life after heart transplantation. Progress in Cardiovascular Diseases, 5, 405-418.

Svenaeus, F. (2012). Organ transplantation and personal identity: how does loss and change of or- gans affect the self? Journal of Medicine and Philosophy, 37, 139-158.

Tokarska, U. (2002). Narracja autobiograficzna w terapii i promocji zdrowia [Autobiographical narrative in therapy and promotion of health]. In: J. Trzebiński (ed.), Narracja jako sposób rozumienia świata [Narrative as a way to understand the world] (pp. 221-261). Gdansk: Gdańskie Wydawnictwo Psychologiczne.

Tuval-Mashiach, R., \& Calhoun, L. (2004). Posttraumatic growth. Conceptual foundations and empirical evidence. Psychological Inquiry, 15, 1-18.

van Minnen, A., Wessel, I., Dijkstra, T., \& Roelofs, K. (2002). Changes in PTSD patients' narratives during prolonged exposure therapy: a replication and extension. Journal of Traumatic Stress, 15, 255-258.

White, M., \& Epston, D. (1990). Narrative means to therapeutic ends. New York, London: W.W. Norton \& Company. 